\title{
The influence of soil communities on the temperature sensitivity of soil respiration
}

Article

Accepted Version

Johnston, A. S. A. and Sibly, R. M. (2018) The influence of soil communities on the temperature sensitivity of soil respiration. Nature Ecology \& Evolution, 2. pp. 1597-1602. ISSN 2397334X doi: https://doi.org/10.1038/s41559-018-0648-6 Available at https://centaur.reading.ac.uk/78849/

It is advisable to refer to the publisher's version if you intend to cite from the work. See Guidance on citing.

To link to this article DOI: http://dx.doi.org/10.1038/s41559-018-0648-6

Publisher: Nature

All outputs in CentAUR are protected by Intellectual Property Rights law, including copyright law. Copyright and IPR is retained by the creators or other copyright holders. Terms and conditions for use of this material are defined in the End User Agreement.

\section{www.reading.ac.uk/centaur}

\section{CentAUR}

Central Archive at the University of Reading

Reading's research outputs online 
1 The influence of soil communities on the temperature sensitivity of soil respiration

2 Alice S.A. Johnston ${ }^{1 *}$, Richard M. Sibly ${ }^{1}$

$4 \quad{ }^{1}$ School of Biological Sciences, University of Reading, UK.

5 * Corresponding Author:

$6 \quad$ alice.johnston@reading.ac.uk; +44 (0)118 3786439

School of Biological Sciences, University of Reading, Reading, RG6 6AH

Soil respiration represents a major carbon flux between terrestrial ecosystems and the atmosphere, and is expected to accelerate under climate warming. Despite its importance in climate change forecasts, however, our understanding of the effects of temperature on soil respiration $\left(R_{S}\right)$ is incomplete. Using a metabolic ecology approach we link soil biota metabolism, community composition and heterotrophic activity, to predict $\boldsymbol{R}_{S}$ rates across five biomes. We find that accounting for the ecological mechanisms underpinning decomposition processes predicts climatological $\boldsymbol{R}_{S}$ variations observed in an independent dataset $(n=312)$. The importance of community composition is evident because without it $\boldsymbol{R}_{S}$ is substantially underestimated. With increasing temperature, we predict a latitudinal increase in $\boldsymbol{R}_{S}$ temperature sensitivity, with $Q_{10}$ values ranging between $2.33 \pm 0.01$ in tropical forests to $2.72 \pm 0.03$ in tundra. This global trend has been widely observed, but has not previously been linked to soil communities.

Soils store the majority of Earth's terrestrial carbon, and so play a crucial role in the direction and magnitude of future climate changes ${ }^{1}$. However, the influence of ongoing climate change on the soil carbon sink is a major area of uncertainty ${ }^{2-4}$. Temperature-associated increases in the global soil $\mathrm{CO}_{2}$ flux (soil respiration, $R_{S}$ ) has led to the supposition that global warming will drive a positive soilclimate feedback ${ }^{5,6}$. Of particular concern is the potential long-term vulnerability of large soil $C$ stocks at high latitudes ${ }^{7}$. However, our incomplete understanding of the temperature $-R_{S}$ relationship limits constrained forecasts of terrestrial carbon fluxes in the future ${ }^{8}$.

The temperature sensitivity of $R_{S}$ across ecosystems is a key determinant of the soil-climate feedback, but it is difficult to quantify due to the many confounding factors that affect soil metabolic rates $^{2,9}$. For instance, $Q_{10}$ values (the proportional increase in $R_{S}$ with a $10{ }^{\circ} \mathrm{C}$ increase in temperature) are highly variable across different vegetation types and climates ${ }^{2,10}$. Nevertheless, Earth system models (ESMs) typically assume a globally constant temperature sensitivity by incorporating fixed $Q_{10}$ values of around 2 (that is, $R_{S}$ rates double with an increase in temperature of $\left.10^{\circ} \mathrm{C}\right)^{11,12}$. Thus, while there is a growing consensus that future warming will enhance $R_{S}$ rates, 
established $^{13,14}$. Here, we propose that a better understanding of $R_{S}$ temperature sensitivity can be gained by accounting for the various organisms that live in the soil.

Soil respiration is the biotic conversion of organic $\mathrm{C}$ to $\mathrm{CO}_{2}$ by all of the organisms (heterotrophs: soil microbes and fauna, and autotrophs: plant roots and their mycorrhizal symbionts) that live in the soil. Thus, $R_{S}$ rates are the product of the body sizes, metabolic rates, abundances and community composition of soil-inhabiting organisms ${ }^{15-18}$. Because individual metabolic rates exhibit varying temperature sensitivities ${ }^{19}$, we would also expect $R_{S}$ responses to increasing temperatures to fluctuate according to soil community composition. However, empirical quantification of soil biota contributions to $R_{S}$ at large spatio-temporal scales is complicated by the vast biodiversity and complexity of soil systems ${ }^{20}$.

In this study, we use a model derived from metabolic theory ${ }^{21}$ to integrate soil biota metabolism, community composition and heterotrophic activity in $R_{S}$ estimates across biomes. The model accounts for the way in which metabolic rates vary with temperature and body size between soil community groups. We then extrapolate to heterotrophic respiration $\left(R_{H}\right)$ rates by accounting for the abundance of soil biota across tundra, boreal forest, temperate forest, temperate grassland and tropical forest soils. By quantifying the contribution of $R_{H}$ to $R_{S}$, using an $R_{H}$ fraction $\left(H_{F}\right)$ which accounts for autotrophs (plant roots and their symbiotic mycorrhizae) not modelled here, we predict $R_{S}$ across biomes and mean annual temperature (MAT) ranges. To test the hypothesis that soil community traits strongly influence $R_{S}$ temperature sensitivities, we compare models that do or do not account for metabolic variation of soil biota. To test how predictive our approach is, we make a further comparison with a classical linear regression fitted to the $R_{S}$ data. Finally, we increase studyspecific MAT's by $10^{\circ} \mathrm{C}$ to compare $\mathrm{Q}_{10}$ estimates with available data across the five biomes, and discuss how these compare to those $Q_{10}$ 's used in ESMs and observed in long-term field experiments.

\section{Results}

\section{Metabolic ecology of soil communities}

68 Metabolism underpins fundamental mechanisms of organism-environment interactions, and sets the basis for linking individual to ecosystem processes ${ }^{22}$. To investigate the temperature sensitivities of metabolism for diverse soil communities, we compiled a metabolic dataset for fourteen soil biota groups (bacteria, protozoa, nematode, collembola, enchytraeidae, acari, ant, beetle, isopod, centipede, spider, termite, millipede, earthworm). The dataset $(n=3768)$ covers nearly 15 orders of magnitude in body mass $(M)$ and temperatures $(T)$ between -2 and $40^{\circ} \mathrm{C}$. In the first instance, the 
metabolic dataset was fitted to the linear form of the metabolic scaling equation without accounting for variations in metabolic parameters between soil biota (termed the 'general' model herein):

$$
\ln (B)=\ln \left(B_{0}\right)+a \ln (M)-E / k T
$$

where $B$ is standard metabolic rate $\left(\mathrm{J} \mathrm{hr}^{-1}\right), B_{0}$ is a taxon-specific normalisation constant, $a$ represents the allometric scaling exponent which usually takes a value close to $3 / 4, E$ is the activation energy $(\mathrm{eV}), k$ is Boltzmann's constant $\left(8.62 \times 10^{-5} \mathrm{eV} \mathrm{K}^{-1}\right)$ and $T$ is experimental temperature $(\mathrm{K})^{21}$. General model (Equation (1)) regression analysis yields an allometric exponent, a, of $0.81( \pm 0.002)$ and activation energy, $E$, of $0.67( \pm 0.01)$ (Supplementary Table 1). Both metabolic parameters are within the range predicted by the metabolic theory of ecology (MTE), $a$ : $0.67-1$ and $E: 0.6-0.7 \mathrm{eV}^{23,24}$. Yet, while the general model predicts metabolic rates with individual body mass well, it does not capture the apparent high variation in soil biota temperature sensitivities (Supplementary Figure 1), indicating the need to account for metabolic traits between soil community groups.

Soil biota were classified into community groups according to their body size distribution as microbes $(<0.0001 \mathrm{mg} \mathrm{FM})$, mesofauna $(0.0001-8 \mathrm{mg} \mathrm{FM})$ or macrofauna ( $8 \mathrm{mg} F \mathrm{~F})$. Microbes include bacteria, mesofauna include protozoa, nematode, acari, collembola and enchytraeidae groups, and macrofauna include ant, spider, isopod, centipede, beetle, termite, millipede and earthworm groups. Although protozoa and nematodes are technically classified as microfauna rather than mesofauna, the metabolic data for these groups were collected at a single experimental temperature. Thus, regression analysis by soil biota groupings was not possible. The community group (CG) model includes two-way interaction terms between $C G$ - body mass and CG temperature to yield community-specific metabolic parameters $\left(B_{0}, a \& E\right)$ :

$$
\ln \left(B_{\mathrm{CG}}\right)=\ln \left(B_{O C G}\right)+a_{\mathrm{CG}} \ln (\mathrm{M})-E_{\mathrm{CG}}(1 / k T)
$$
(Figs. 1a \& b, Supplementary Table 1). Interestingly, analysis of the CG model reveals that the temperature sensitivity of metabolism $(E)$ increases with decreasing body size, from $0.64( \pm 0.01)$ for macrofauna to $0.74( \pm 0.19)$ for microbes (Supplementary Table 1). That is, smaller sized soil community groups exhibit a greater proportional increase in their metabolic rates with a given increase in temperature, than individuals belonging to larger size community groups. This suggests a higher contribution of soil microbes (in particular, as mass-specific metabolic rates in mesofauna are lower) to $R_{S}$ rates at increasing temperatures, if resources are available to fulfil higher energy 
111

112 113 mass and temperature, Figs. 1c \& d) and fitted lowess line, further indicate an absence of systematic errors, which are much greater for the general model (Supplementary Figure 1).
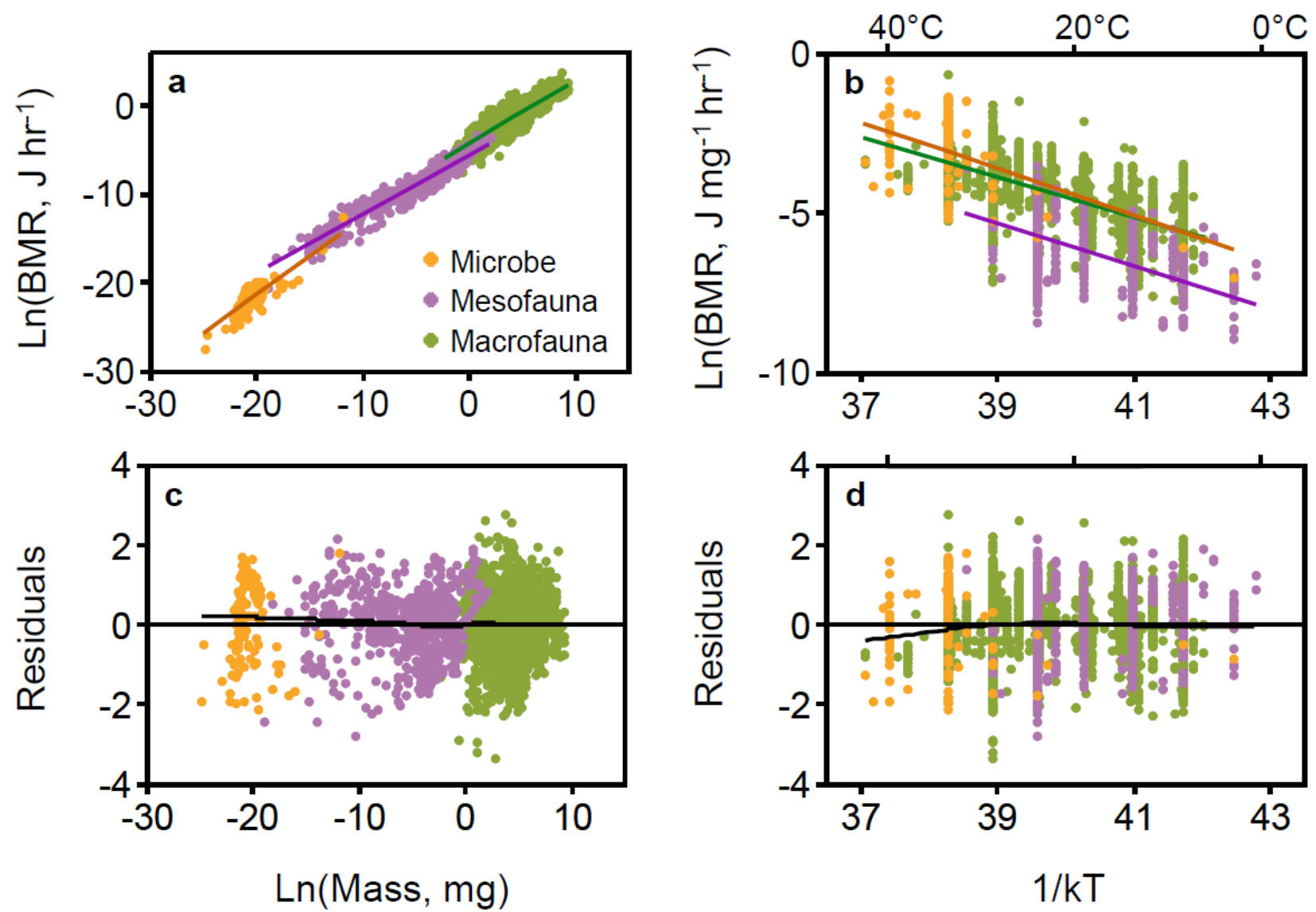

\section{Ln(Mass, mg)}

Figure 1. Metabolic scaling relationships in soil communities. Left-hand plots (a \& $\mathrm{c})$ show individual metabolic rates $(B)$, corrected to a temperature of $20^{\circ} \mathrm{C}$ using equation (2), plotted against individual body mass $(M$, mg FM). Right-hand plots ( $b \& d$ ) show $B$, corrected to a body mass of $1 \mathrm{mg}$ using equation (2), plotted against temperature in an Arrhenius plot. Top plots ( $\mathrm{a} \& \mathrm{~b}$ ) show community group (CG) model predictions of metabolic rates with individual body mass and temperature, and bottom plots (c \& d) show distributions of the CG model residuals, with deviations of the data from model predictions characterised by lowess fits (black curves). Microbes (orange) include bacteria, mesofauna (purple) include protozoa, nematodes, acari, collembola and enchytraeidae, and macrofauna (green) include ant, spider, isopod, centipede, beetle, termite, millipede and earthworm groups $(n=3768)$. Metabolic parameter values are provided in Supplementary Table 1.

\section{Linking soil metabolism to biome-specific $\boldsymbol{R}_{S}$ rates}

Linking the individual metabolic rates of soil biota to biome-specific $R_{S}\left(\mathrm{~g} \mathrm{C} \mathrm{m}^{-2}\right.$ year $\left.^{-1}\right)$ requires quantification of soil biota population abundances $\left(A\right.$, no. $\left.\mathrm{m}^{-2}\right)$ and $R_{H}$ fractions $\left(H_{F}\right.$, which measure the proportion of $R_{S}$ contributed by heterotrophs and so also accounts for autotrophs) across biomes. First, individual-level metabolic rates ( $B$, as in equation (2)) for each soil biota group $(i)$ were calculated for an individual of average body mass $(M)$ at a given MAT $(T)$. $B$ is then converted to respiration rate units $\left(\mathrm{g} \mathrm{C} \mathrm{yr}^{-1}\right)$ by using the conversion factors $37490 \mathrm{~J} \mathrm{gC}^{-1}=20100 \mathrm{~J} \mathrm{LO}_{2}^{-1} \times(1 /$ $\left.0.5363 \mathrm{~g} \mathrm{C} \mathrm{LO}_{2}{ }^{-1}\right)^{25,26}$ and $8760 \mathrm{hr} \mathrm{yr}^{-1}$. The heterotrophic respiration rate $\left(R_{H}\right)$ is the soil 
133 community's respiration rate, which is calculated according to individual-level respiration rates $\left(r_{i}\right)$

134 and population abundance $\left(\mathrm{A}_{i}\right)$ as: $R_{H}=\sum_{i} r_{i} A_{i}$, where the summation is over the soil biota groups 135 in the biome. Our $R_{H}$ predictions are compared to independent data in Supplementary Figures 2 \& 136 3. Finally, accounting for $H_{F}$ 's reported in the Bond-Lamberty and Thomson ${ }^{27}$ dataset 137 (Supplementary Figure 4, $\mathrm{n}=66$ ) gives: $R_{S}=\frac{1}{H_{F}} \sum_{i} r_{i} A_{i} . R_{S}$ was calculated at MAT for each of the $138 R_{S}$ studies used to evaluate our approaches predictions $(\mathrm{n}=312)$, using metabolic parameters, 139 individual body masses and soil biota population abundances in Supplementary Tables 2, 3 \& 4 140 respectively.

\section{Soil community composition across biomes}

143 Population biomass ( $\mathrm{g} \mathrm{FM} \mathrm{m}^{-2}$ ) and abundance (number $\mathrm{m}^{-2}$ ) measurements for the fourteen soil 144 biota groups for which metabolic data is available were collected across tundra, boreal forest, 145 temperate forest, temperate grassland and tropical forest soils $(n=2187)$. Community group 146 biomasses across the five biomes investigated here were significantly different $(p=0.000$, 147 Supplementary Table 5). In general, high latitude (tundra and boreal) soils harbour more soil 148 microbes and mesofauna by biomass than temperate and tropical soils. Soil macrofauna follow an 149 inverse trend, increasing in biomass from tundra to temperate grasslands and tropical forests (Fig. 150 2). Given the higher temperature sensitivity of smaller sized soil biota (Fig. 1), we would expect 151 higher abundances of soil microbes and mesofauna in tundra and boreal soils to be linked to higher $152 R_{S}$ temperature sensitivities at high latitudes. 


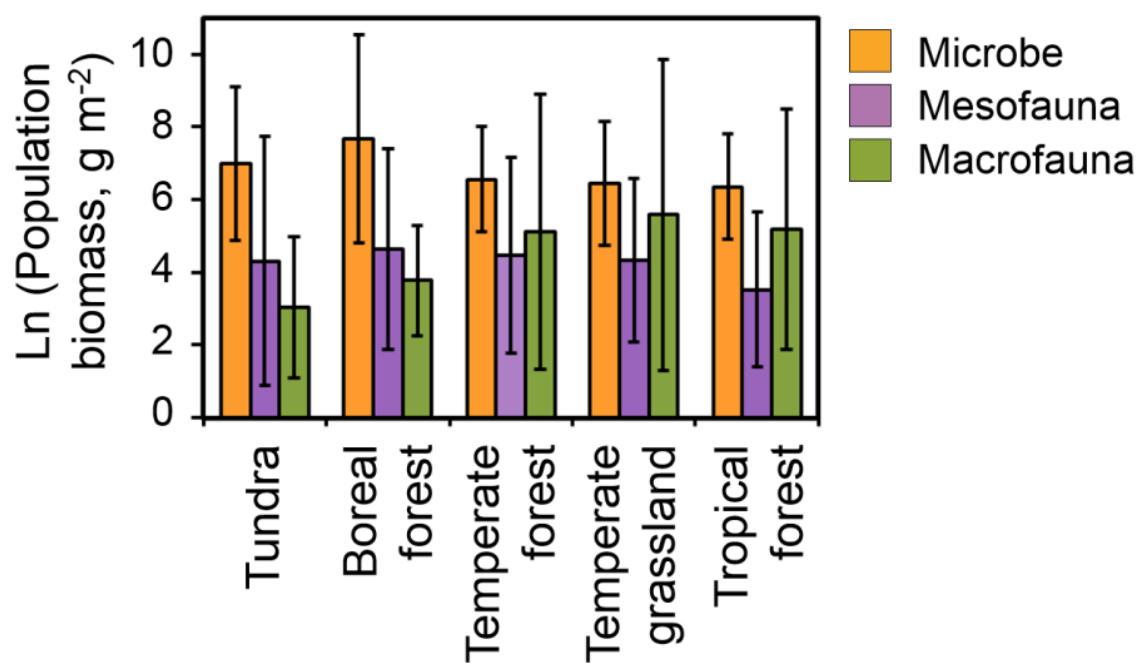

Figure 2. Soil community composition across biomes. Soil community groups are classified by body size distribution (microbe, mesofauna and macrofauna). Biomass ( $\mathrm{g}$ fresh mass $\mathrm{m}^{-2}$ ) measurements incorporate the sum of soil biota population biomasses for each community group. Average biome-specific soil microbial biomasses were taken from the study of Xu et al. ${ }^{28}$, while soil mesofauna and macrofauna data were compiled in this study ( $n=2187$, Supplementary

Figure ). Presented values are means \pm reported standard errors for microbes, while error bars for mesofauna and macrofauna were calculated as the square root of the summed variances for soil biota group population biomasses. Differences in community group biomass are significantly different across biomes ( $p=0.000$, Supplementary Table 5).

\section{The influence of soil communities on $\boldsymbol{R}_{S}$ across biomes}

Comparison of our $R_{S}$ predictions (lines) with independent $R_{S}$ data (symbols) in Fig. 3a demonstrates good prediction of $R_{S}$ rates across biomes and MAT's $\left(R^{2}=0.66, \mathrm{n}=312\right.$, no $p$-value can be reported as predictions are independent of the data). Temperature sensitivity differences across biomes emerge from the approach by integrating variation in the metabolic ecology and community composition of soils. However, high variability in the $R_{S}$ data likely points to site-specific interactions between individual, population and community-level dynamics with other environmental factors (e.g. resource quantity and quality), as well as temperature (Fig. 3b). 


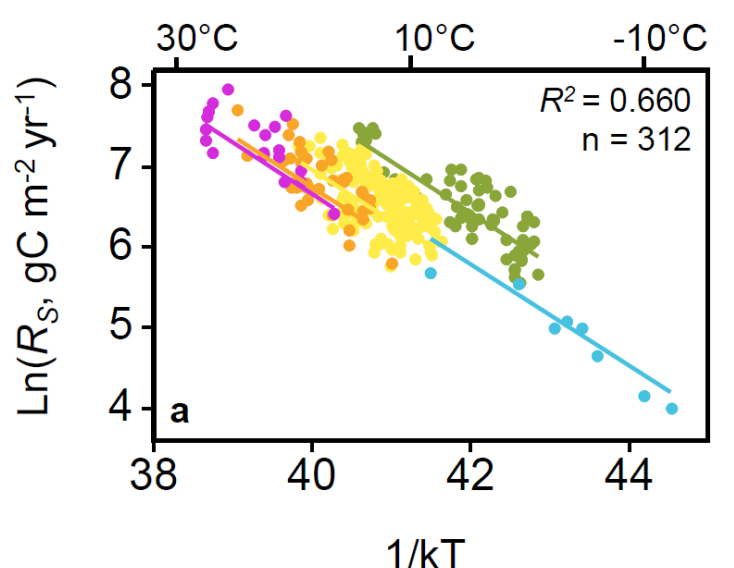

$1 / k T$

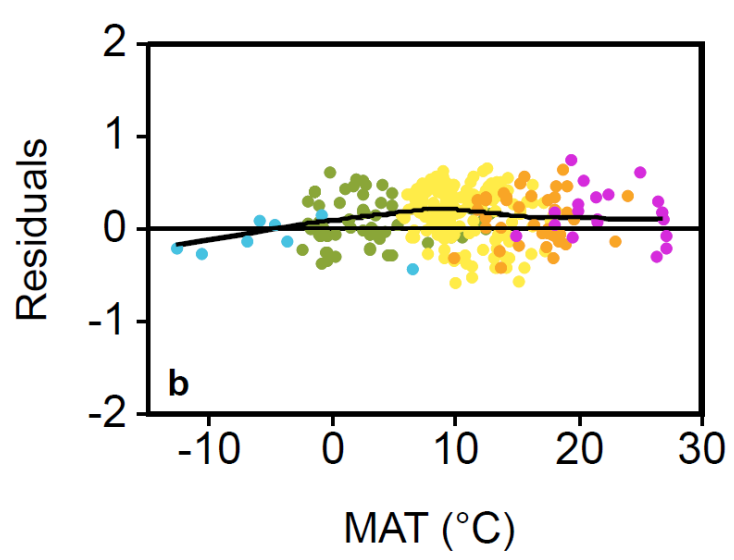

Temperate forest

\section{$\operatorname{MAT}(\mathrm{C})$}

- Tropical forest - Temperate grassland

Figure 3. Temperature sensitivity of soil respiration $(\boldsymbol{R} s)$ across biomes and MAT's. Plots show a) independent $R_{S}$ data (symbols: $\mathrm{n}=312$ ) and predicted $R$ s from the community group $(C G)$ model presented here (lines) and b) $C G$ model residual distributions against MAT $\left({ }^{\circ} \mathrm{C}\right)$ with fitted lowess line (solid black line).

To test whether incorporating the varying temperature sensitivities of soil biota was important in achieving good $R_{S}$ predictions (Fig. 3 and $4 \mathrm{a}$ ), we compare the CG model presented here to $R_{S}$ predictions using the general model (Fig. 4b) and a linear regression between $R_{S}$ and MAT fitted to the data (Fig. 4c). Not accounting for metabolic variation between soil community groups in the general model significantly reduces the accuracy of the metabolic approach (Fig. 4b). This result indicates that soil community body size distribution and metabolic ecology strongly influence the temperature sensitivity of $R_{S}$ across the five biomes investigated here. Comparison of the CG model with the linear regression $\left(\operatorname{Ln}\left(R_{S}\right)=22.54-0.388(1 / \mathrm{kT})\right.$, Fig. 4C) and AIC values, further indicates that accounting for soil ecology enables better $R_{S}$ predictions. Improved prediction of $R_{S}$ rates are particularly evident in boreal and tundra soils of the CG model, where the data indicate higher $R_{S}$ temperature sensitivity (Fig. 3a). Weak temperature control in the linear regression presented here and ESMs which implement fixed $Q_{10}$ values are unable to capture these climatological differences in $R_{S}$ temperature sensitivities ${ }^{7}$, with serious consequences for future climate change projections. 
a

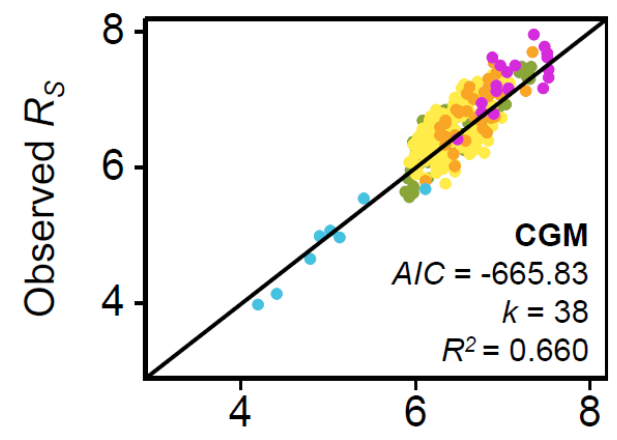

b

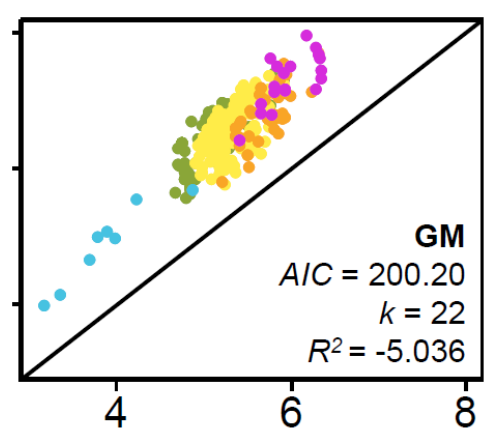

Predicted $R_{S}$ c

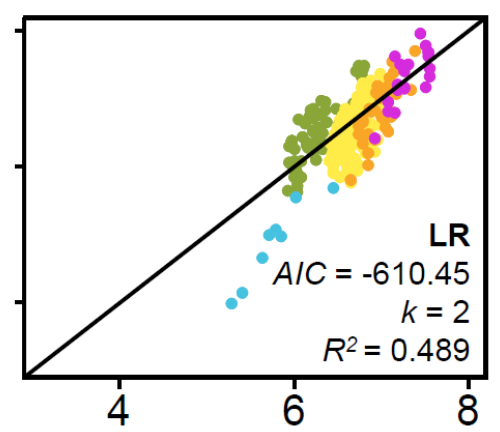

3

- Tropical forest

Temperate grassland

Temperate forest

- Boreal forest - Tundra

Figure 4. Model comparisons and goodness of fits with independent soil respiration $\left(R s, \mathrm{gC}^{-2}\right.$ year $\left.^{-1}\right) \mathrm{data}$. The community group model (CGM) (a) is compared to the general metabolic model (GM) (b) which does not account for metabolic variation in soil communities, and an empirical fitted linear regression (LR) to the $R s$ data $(\operatorname{Ln}(R s)=22.54-$ $\left.0.388(1 / k T), r^{2}=0.489, p<0.0001\right)$ (c). $p$-values cannot be calculated for $a \& b$ as predictions are independent of the data. Solid black lines are 1:1 lines which would demonstrate perfect prediction and lower AIC values indicate a better goodness of fit to the data while accounting for model complexity ( $k$ : number of parameters). Note that the $r^{2}$ value for the general model $(b)$ is negative because the residual sum of squares from the model is higher than the total sum of squares from the data.

Biome-specific $Q_{10}$ 's were calculated, using the CG model, by taking $R_{S}$ rates for study-specific MAT's (MAT $0, n=119)$ and for an increase in temperature of $10^{\circ} \mathrm{C}\left(\mathrm{MAT}_{+10}\right)$, to give $\mathrm{Q}_{10}=$ $R_{S}\left(\mathrm{MAT}_{+10}\right) / R_{S}\left(\mathrm{MAT}_{0}\right)$. We compare our median $\mathrm{Q}_{10}$ values (symbols) to those reported in the Bond-Lamberty and Thomson ${ }^{27}$ dataset (boxes) in Fig. 5. With increasing temperature, the metabolic approach indicates that $R_{S}$ in tundra and boreal soils is more temperature sensitive than temperate and tropical soils, with mean $Q_{10}$ values increasing from $2.33 \pm 0.001$ in tropical forests to $2.72 \pm 0.03$ in tundra. Many studies have reported similar climatological responses, in which $R_{S}$ in colder high latitude climates increase more rapidly with increasing temperature ${ }^{7,8,10,27,29-33}$, but none have yet linked variations in $R_{S}$ temperature sensitivity to the mechanisms driving decomposition processes by soil communities. However, our estimates also assume static biome-specific soil communities, and that greater metabolic rates at higher temperatures are met with sufficient food resources.

Temperature, soil water and resource availability interact to affect the provision of food resources to soil communities ${ }^{34}$, and the inclusion of these environment-community feedbacks would likely result in lower $R_{S}$ sensitivity predictions in warm climates as the soil biota become food limited ${ }^{15}$.

Conversely, freeze-thaw cycles in tundra soils lead to deviation of $R_{S}$ temperature dependence from thermodynamic laws ${ }^{7}$, increasing below $0^{\circ} \mathrm{C}$ as the decomposition of structurally complex molecules by arctic microbes exhibit a higher temperature sensitivity of metabolism ${ }^{35}$. Our $\mathrm{Q}_{10}$ 
219 estimates thus overestimate tropical soil and underestimate tundra and boreal soil responses to 220 increasing temperatures (Fig. 5), in line with long-term field $Q_{10}$ 's of $5.2 \pm 2.4$ for tundra and boreal, $2212.7 \pm 1.7$ for temperate and $2.2 \pm 0.9$ for tropical climates ${ }^{36}$. Exploring alternative thermodynamic 222 hypotheses, such as non-linear temperature curves and acclimatisation mechanisms, could explain 223 more of the variability in the $Q_{10}$ data and $Q_{10}$ 's under long-term warming. On the other hand, our 224 approach estimates much higher $Q_{10}$ values than the static value of 2 used in many ESMs, which 225 are often parameterised with short-term observations based on eddy covariance fluxes and soil 226 incubations ${ }^{2,37}$. This divergence between short- and long-term $Q_{10}$ values has been suggested as 227 evidence for the inclusion of emergent behaviour over long timescales ${ }^{7}$, which in this study includes 228 the metabolic response of soil communities and shifts in soil community composition across biomes.

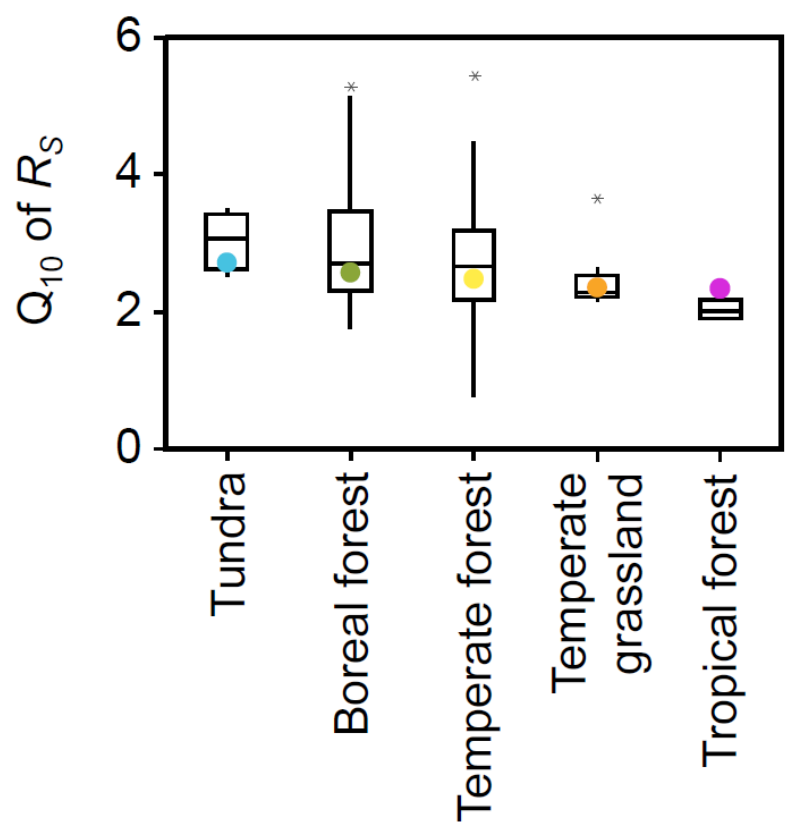

Figure 5. Observed and predicted $Q_{10}$ values for $R$ s across biomes. $Q_{10}$ data from the Bond-Lamberty and Thomson across biomes are given by coloured symbols, showing median predicted values, with imperceptible first and third quartile whiskers.

\section{Discussion}

We use a metabolic ecology approach to better understand the relationships between soil biota metabolism, community composition and $R_{S}$ rates. We find that accounting for the metabolic ecology of soils (Fig. 1) together with soil community composition (Fig. 2) reveals variations in $R_{S}$ with MAT across five biomes (Fig. 3). Important in achieving good $R_{S}$ predictions was incorporating the varying temperature sensitivities of soil community groups. In comparison, assuming all soil 242 biota exhibit identical temperature sensitivities resulted in substantial under-estimation of $R_{S}$ rates 243 (Fig. 4b). The metabolic ecology and body size distribution of soil communities thus strongly 
244 influence the temperature sensitivity of $R_{S}$ across biomes. With increasing temperature, our 245 approach suggests that $R_{S}$ would be most strongly enhanced in colder climatic regions (Fig. 5),

246 because of the higher temperature sensitivity of soil biota inhabiting these soils.

248 Soil community composition will also be influenced by multiple global drivers (e.g. warming, $\mathrm{CO}_{2}$ 249 fertilisation, $\mathrm{N}$ deposition) in the future, which will alter the direction and magnitude of $R_{S}$ responses. 250 Thus, to better anticipate the effects of global environmental changes on $R_{S}$ requires a better 251 understanding of the ecological mechanisms underpinning macroecological patterns in soil 252 communities. Yet, fundamental knowledge gaps in soil ecology need to be addressed to understand 253 the primary drivers of soil community composition across a broad spectrum of environmental 254 variables. Unravelling these complex interactions would allow us to represent the mechanistic links 255 between the belowground and aboveground components of terrestrial ecosystems, develop more 256 predictive models of soil systems and improve forecasts of future climate changes on numerous ecosystem functions, including $R_{S}$. Our study stresses the importance of considering the soil organisms which facilitate ecosystem functions, and demonstrates the utility of fundamental ecological principles in describing complex soil systems.

\section{Methods}

262 Metabolic ecology of soil biota. Metabolic data for a wide range of soil biota was compiled from 263 the dataset of Ehnes, et al. ${ }^{19}$, which includes data from the meta-analyses of Meehan ${ }^{38}$ and 264 Chown, et al. ${ }^{39}$ together with their own measurements for acari, collembola, enchytraeidae, 265 centipedes, millipedes, isopods, spiders, ants, beetles, termites and earthworms $(n=3399)$. In 266 addition, we compiled data for bacteria from Makarieva, et al. ${ }^{40}(n=56)$, protozoa from Laybourn and Finlay ${ }^{41}$ and Fenchel and Finlay ${ }^{42}(n=143)$, nematodes from Klekowski, et al. ${ }^{43}$ and Ferris, et al. ${ }^{44}(n=105)$ and enchytraeidae from Nielsen ${ }^{45}(n=58)$. Detailed differences at the species-level are avoided in order to explore the collective metabolism of soil community groups across biomes. All measurements were converted to wet weight $(\mathrm{mg})$ and standard metabolic rate per hour $\left(\mathrm{J} \mathrm{hr}^{-1}\right)$, using a dry to fresh mass ratio of $0.2: 1^{19}, 1 \mathrm{~mL} \mathrm{O}_{2}=20.1 \mathrm{~J}^{26}$ and $1 \mathrm{~mL} \mathrm{O}_{2}=0.5363 \mathrm{mg} \mathrm{C}^{25}$.

Soil biota populations and community composition. Linking individual to population-level metabolism requires estimation of the population abundances of different soil biota across biomes. Here, we extend the dataset of Fierer, et al. ${ }^{46}$, who collected population biomass data for acari, collembola, enchytraeidae, nematodes and earthworms in tundra, boreal forest, temperate forest, temperate grassland and tropical forest soils $(n=799)$. We compiled additional data for all of the soil biota groups and biomes of Fierer, et al. ${ }^{46}$, and for ants, beetles, centipedes, isopods, 279 millipedes, protozoa, spiders and termites in biomes for which data was available $(n=1382)$. 280 Average biome-specific microbial biomass values were taken from the extensive review of $\mathrm{Xu}$, et al. 
28, which compiles 1182 measurements across the biomes investigated here (Supplementary Table 4).

Population biomass measurements required conversion to population abundance by estimates of mean individual body masses $(M)$ for the fourteen different soil biota groups. We assume that $M$ for different soil biota groups are constant across biomes. Although this assumption likely introduces error due to variations in individual life histories across climates, not enough information exists to apply more detailed individual-level relationships. To minimise error we collated data from a number of sources reporting $M$ for the different soil biota groups (Supplementary Table 3). Average $M$ (mg dry mass) used in this study were: protozoa $\left(6.55 \times 10^{6}\right)$, nematodes $(0.0020)$, acari $(0.0096)$, collembola (0.055), enchytraeidae (0.055), ants (2.23), beetles (4.35), isopods (4.47), centipedes (6.59), spiders (7.42), termites (9.90), millipedes (17.06) and earthworms (52.37). All population biomass measurements are expressed here as fresh mass $\left(\mathrm{g} \mathrm{FM} / \mathrm{m}^{2}\right)$ using the conversion to fresh mass of five times dry mass ${ }^{19}$. Using a single dry to fresh mass conversion factor for all soil biota groups will also introduce some error, as variations likely exist across soil biota groups and biomes ${ }^{47}$. Measurements given in the dataset of Fierer et al. ${ }^{46}\left(\mathrm{~g} \mathrm{C} \mathrm{m}^{-2}\right)$ were further corrected by accounting for a $50 \%$ carbon content. We do not make additional extrapolations to specific soil depths, as this is highly variable between soil biota groups and soil types, and often not reported in field studies. If population measurements were expressed on per mass of dry soil basis, appropriate bulk density values were used to convert these measurements to density (per $\mathrm{m}^{2}$ ) for the soil type

Heterotrophic respiration $\left(\boldsymbol{R}_{H}\right)$. Using our metabolic approach, $R_{H}$ rates were estimated by summing the metabolic rates of soil communities at MAT in a given biome. Community-level metabolic rates were calculated by taking metabolic parameters $\left(B_{0}\right.$, $a$ and $E$; Supplementary Table 1) for each soil community group, individual body masses $(M, \mathrm{mg}$ fresh mass) for each soil biota group (Supplementary Table 3 ) and their population abundance $\left(A\right.$, number $\left.\mathrm{m}^{-2}\right)$ in different biomes (Supplementary Table 4). Metabolic rates were then transformed to respiration rates ( $\mathrm{g} \mathrm{C}$ ) by using the conversion factors $37490 \mathrm{~J} \mathrm{gC}^{-1}=20100 \mathrm{~J} \mathrm{LO}_{2}^{-1} \times\left(1 / 0.5363 \mathrm{~g} \mathrm{C} \mathrm{LO}_{2}^{-1}\right)^{25,26}$ and $8760 \mathrm{hr} \mathrm{yr}^{-1}$. To investigate whether our model predicts $R_{H}$ rates across biomes and MAT's, prior to extrapolating to $R_{S}$ as detailed below, we compared our predictions with available $R_{H}$ data in the Bond-Lamberty and Thomson ${ }^{27}$ dataset $(\mathrm{n}=66)$. $R_{H}$ data were compiled for un-manipulated field studies reporting annual $R_{H}$ and $R_{S}$ rates, and were averaged for single study years and/or locations where applicable. Measurements were also excluded if reported $R_{H}$ rates were equal to or higher than reported $R_{S}$ rates. If MAT's were not reported, or the same MAT was given for multiple years in the same study, NOAA weather stations were used to collect MAT measurements based on the study sites latitude and longitude (https://www.ncdc.noaa.gov/cdo-web/datatools/findstation). The CG 
318 model's predictions of $R_{H}$ rates were then evaluated $\left(r^{2}=0.757\right.$, Supplementary Figure 2$)$, in 319 comparison to the general metabolic model $\left(r^{2}=-2.261\right)$ and a linear regression approach $\left(r^{2}=\right.$ 320 0.529) (Supplementary Figure 3). Accounting for model complexity in $A / C$ calculations indicates that the CG model does not perform better than the linear regression given its large number of parameters, but this may be a result of the limited size of the data set. To test whether the CG approach performs better given more data we used the $R_{H}$ data to calculate an $R_{H}$ fraction $\left(H_{F}\right)$ for each biome to account for the contribution of heterotrophs to $R_{S}$. This allowed us to use the larger $R_{S}$ data set $(\mathrm{n}=312)$ to evaluate the $C G$ model with greater precision as reported in Fig. 4 .

\section{$R_{H}$ fraction $\left(H_{F}\right)$}

$328 R_{H}$ fractions $\left(H_{F}\right)$ were calculated as $R_{H} / R_{S}$ for studies reporting both annual $R_{H}$ and $R_{S}$ rates (g C $\mathrm{m}^{-2}$ year ${ }^{-1}, \mathrm{n}=66$ ) and assuming $R_{S}=R_{H}+R_{A}^{48}$. By using $R_{H}$ values, rather than $R_{A}$, we avoid some of the issues in separating heterotrophic and autotrophic contributions to $R_{S}$, as $R_{H}$ is typically measured directly whereas $R_{A}$ is typically derived by calculating the difference between $R_{S}$ and other ecosystem fluxes ${ }^{48}$. Mean $H_{F} \pm S E$ across the five biomes investigated here were $0.39 \pm 0.10$, $0.63 \pm 0.02,0.58 \pm 0.03,0.63 \pm 0.04$ and $0.77 \pm 0.07$ for tundra, boreal forest, temperate forest, temperate grassland and tropical forest soils, respectively. Variability in $H_{F}$ within biomes is likely linked to the experimental difficulties associated with separating the autotrophic and heterotrophic components of soils and the methodology used to do so in the field ${ }^{48-50}$. To explain some of this variability, and to account for the temperature sensitivity of $R_{A}$, we performed a regression analysis between $H_{F}$ and MAT, which revealed a weak but significant positive correlation $\left(H_{F}=0.54+0.0069\right.$ MAT; $r^{2}=0.104, p=0.008$, Supplementary Figure 4). This linear relationship is incorporated in our calculations to extrapolate from $R_{H}$ to $R_{S}$ rates across biomes and MAT's.

\section{Soil respiration $\left(R_{S}\right)$}

343 To compare our $R_{S}$ estimates with independent data, annual $R_{S}$ rates $\left(\mathrm{g} \mathrm{C} \mathrm{m}^{-2} \mathrm{yr}^{-1}\right)$ were compiled 344 from the global soil respiration datasets of Bond-Lamberty and Thomson ${ }^{27}$ and Carey, et al. ${ }^{51}$ for 345 tundra, boreal forest, temperate forest, temperate grassland and tropical forest soils $(n=312)$. Data 346 were included from un-manipulated field studies reporting average annual $R_{S}$ and MAT, and 347 measurements from both datasets were averaged for single study years and/or locations where 348 applicable. $R_{S}$ measurements compiled from the Bond-Lamberty and Thomson ${ }^{27}$ dataset included $349119 Q_{10}$ values, which were used to evaluate predicted $Q_{10}$ 's across biomes using our CG model.

351 Data availability. The datasets generated and analysed during the current study are available on

\section{Dryad (https://doi.org/10.5061/dryad.416kv03).}




\section{References}

354

355

356

357

358

359

360

361

362

363

364

365

366

367

368

369

370

371

372

373

374

375

376

377

378

379

380

381

382

383

384

385

386

387

388

389

390

391

392

393

394

395

396

397

398

399

400

401

402

403

404

405

406

407

1 Hicks Pries, C. E., Castanha, C., Porras, R. C. \& Torn, M. S. The whole-soil carbon flux in response to warming. Science 355, 1420-1423, doi:10.1126/science.aal1319 (2017).

2 Davidson, E. A. \& Janssens, I. A. Temperature sensitivity of soil carbon decomposition and feedbacks to climate change. Nature 440, 165-173 (2006).

3 Crowther, T. W. et al. Quantifying global soil carbon losses in response to warming. Nature 540, 104-108 (2016).

4 Bradford, M. A. et al. Managing uncertainty in soil carbon feedbacks to climate change. Nature Climate Change 6, 751-758 (2016).

5 Bond-Lamberty, B. \& Thomson, A. Temperature-associated increases in the global soil respiration record. Nature 464, 579-582 (2010).

6 Cox, P. M., Betts, R. A., Jones, C. D., Spall, S. A. \& Totterdell, I. J. Acceleration of global warming due to carbon-cycle feedbacks in a coupled climate model. Nature 408, 184-187 (2000).

7 Koven, C. D., Hugelius, G., Lawrence, D. M. \& Wieder, W. R. Higher climatological temperature sensitivity of soil carbon in cold than warm climates. Nature Climate Change 7 , 817-822 (2017).

8 Giardina, C. P., Litton, C. M., Crow, S. E. \& Asner, G. P. Warming-related increases in soil $\mathrm{CO} 2$ efflux are explained by increased below-ground carbon flux. Nature Climate Change 4, 822-827 (2014).

9 Reichstein, M. et al. On the separation of net ecosystem exchange into assimilation and ecosystem respiration: review and improved algorithm. Global Change Biology 11, 14241439 (2005).

10 Raich, J. W. \& Schlesinger, W. H. The global carbon dioxide flux in soil respiration and its relationship to vegetation and climate. Tellus B 44, 81-99 (1992).

11 Exbrayat, J. F., Pitman, A. J., Zhang, Q., Abramowitz, G. \& Wang, Y. P. Examining soil carbon uncertainty in a global model: response of microbial decomposition to temperature, moisture and nutrient limitation. Biogeosciences 10, 7095-7108 (2013).

12 Yang, J. et al. The role of satellite remote sensing in climate change studies. Nature Climate Change 3, 875-883 (2013).

13 Rustad, L. E. et al. A Meta-Analysis of the Response of Soil Respiration, Net Nitrogen Mineralization, and Aboveground Plant Growth to Experimental Ecosystem Warming. Oecologia 126, 543-562 (2001).

14 Balser, T. C. \& Wixon, D. L. Investigating biological control over soil carbon temperature sensitivity. Global Change Biology 15, 2935-2949 (2009).

15 Thakur, M. P. et al. Reduced feeding activity of soil detritivores under warmer and drier conditions. Nature Climate Change 8, 75-78 (2018).

16 Eisenhauer, N., Cesarz, S., Koller, R., Worm, K. \& Reich, P. B. Global change belowground: impacts of elevated $\mathrm{CO} 2$, nitrogen, and summer drought on soil food webs and biodiversity. Global Change Biology 18, 435-447 (2012).

17 Suttle, K. B., Thomsen, M. A. \& Power, M. E. Species Interactions Reverse Grassland Responses to Changing Climate. Science 315, 640-642 (2007).

18 Yvon-Durocher, G. et al. Reconciling the temperature dependence of respiration across timescales and ecosystem types. Nature 487, $472-476$ (2012).

19 Ehnes, R. B., Rall, B. C. \& Brose, U. Phylogenetic grouping, curvature and metabolic scaling in terrestrial invertebrates. Ecology Letters 14, 993-1000 (2011).

20 Briones, M. J. I., Ostle, N. J., McNamara, N. P. \& Poskitt, J. Functional shifts of grassland soil communities in response to soil warming. Soil Biology and Biochemistry 41, 315-322 (2009).

21 Sibly, R. M., Brown, J. H. \& Kodric-Brown, A. Metabolic Ecology: A Scaling Approach (Wiley-Blackwell, Oxford, 2012).

22 Brown, J. H. \& Sibly, R. M. Metabolic Ecology Ch. 2 (Wiley-Blackwell, Oxford, 2012).

23 Brown, J. H., Gillooly, J. F., Allen, A. P., Savage, V. M. \& West, G. B. Toward a metabolic theory of ecology. Ecology 85, 1771-1789 (2004). 
24 Kozłowski, J., Konarzewski, M. \& Gawelczyk, A. T. Cell size as a link between noncoding DNA and metabolic rate scaling. Proceedings of the National Academy of Sciences 100, 14080-14085 (2003).

25 Lampert, W. The measurement of respiration. A manual on methods for the assessment of secondary productivity in fresh waters 17, 413-468 (1984).

26 Peters, R. H. The ecological implications of body size. Vol. 2 (Cambridge University Press, 1983).

27 Bond-Lamberty, B. \& Thomson, A. A global database of soil respiration data.

Biogeosciences 7, 1915-1926 (2010).

28 Xu, X., Thornton, P. E. \& Post, W. M. A global analysis of soil microbial biomass carbon, nitrogen and phosphorus in terrestrial ecosystems. Global Ecology and Biogeography 22, 737-749 (2013).

29 Karhu, K. et al. Temperature sensitivity of soil respiration rates enhanced by microbial community response. Nature 513, 81-84 (2014).

30 Clein, J. S. \& Schimel, J. P. Microbial activity of tundra and taiga soils at sub-zero temperatures. Soil Biology and Biochemistry 27, 1231-1234 (1995).

31 Dorrepaal, E. et al. Carbon respiration from subsurface peat accelerated by climate warming in the subarctic. Nature 460, 616-619 (2009).

32 Nie, M. et al. Positive climate feedbacks of soil microbial communities in a semi-arid grassland. Ecology Letters 16, 234-241 (2013).

33 Aerts, R. The freezer defrosting: global warming and litter decomposition rates in cold biomes. Journal of Ecology 94, 713-724 (2006).

34 Davidson, E. A., Janssens, I. A. \& Luo, Y. On the variability of respiration in terrestrial ecosystems: moving beyond Q10. Global Change Biology 12, 154-164 (2006).

35 Mikan, C. J., Schimel, J. P. \& Doyle, A. P. Temperature controls of microbial respiration in arctic tundra soils above and below freezing. Soil Biology and Biochemistry 34, 1785-1795 (2002).

36 Chen, H. \& Tian, H. Q. Does a General Temperature-Dependent Q10 Model of Soil Respiration Exist at Biome and Global Scale? Journal of Integrative Plant Biology 47, 12881302 (2005).

37 Mahecha, M. D. et al. Global Convergence in the Temperature Sensitivity of Respiration at Ecosystem Level. Science 329, 838-840 (2010).

38 Meehan, T. D. Mass and temperature dependence of metabolic rate in litter and soil invertebrates. Physiological and biochemical zoology 79, 878-884 (2006).

39 Chown, S. L. et al. Scaling of insect metabolic rate is inconsistent with the nutrient supply network model. Functional Ecology 21, 282-290 (2007).

40 Makarieva, A. M., Gorshkov, V. G. \& Li, B.-L. Energetics of the smallest: do bacteria breathe at the same rate as whales? Proceedings of the Royal Society B: Biological Sciences 272, 2219-2224 (2005).

41 Laybourn, J. \& Finlay, B. J. Respiratory energy losses related to cell weight and temperature in ciliated protozoa. Oecologia 24, 349-355 (1976).

42 Fenchel, T. \& Finlay, B. J. Respiration Rates in Heterotrophic, Free-Living Protozoa. Microbial Ecology 9, 99-122 (1983).

43 Klekowski, R., Wasilewska, L. \& Paplinska, E. Oxygen consumption by soil-inhabiting nematodes. Nematologica 18, 391-403 (1972).

44 Ferris, H., Lau, S. \& Venette, R. Population energetics of bacterial-feeding nematodes: respiration and metabolic rates based on $\mathrm{CO} 2$ production. Soil Biology and Biochemistry 27, 319-330 (1995).

45 Nielsen, C. O. Respiratory metabolism of some populations of enchytraeid worms and freeliving nematodes. Oikos 12, 17-35 (1961).

46 Fierer, N., Strickland, M. S., Liptzin, D., Bradford, M. A. \& Cleveland, C. C. Global patterns in belowground communities. Ecology letters 12, 1238-1249 (2009).

47 Petersen, H. \& Luxton, M. A Comparative Analysis of Soil Fauna Populations and Their Role in Decomposition Processes. Oikos 39, 288-388 (1982). 
46248 Subke, J. A., Inglima, I. \& Francesca Cotrufo, M. Trends and methodological impacts in soil $463 \quad$ CO2 efflux partitioning: a metaanalytical review. Global Change Biology 12, $921-943$ (2006). 46449 Bond-Lamberty, B., Wang, C. \& Gower, S. T. A global relationship between the heterotrophic and autotrophic components of soil respiration? Global Change Biology 10, 1756-1766 (2004).

50 Hogberg, P., Nordgren, A., Buchmann, N. \& Taylor, A. F. Large-scale forest girdling shows that current photosynthesis drives soil respiration. Nature 411, 789 (2001).

51 Carey, J. C. et al. Temperature response of soil respiration largely unaltered with experimental warming. Proceedings of the National Academy of Sciences 113, 13797-13802 (2016).

474 This research has been financially supported by a NERC Soil Security Programme fellowship

475 (NE/N019504/1). We thank Chris Venditti, James Brown, Gabriel Yvon-Durocher, Charles Hall and

476 four anonymous reviewers for their feedback and suggestions on the manuscript.

\section{Author contributions}

479 AJ conceived the idea and compiled and analysed the data; AJ and RS developed the methodology 480 and wrote the manuscript.

\section{Competing interests}

483 The authors declare no competing financial interests. 